This item was submitted to Loughborough's Research Repository by the author.

Items in Figshare are protected by copyright, with all rights reserved, unless otherwise indicated.

\title{
Formation of size-tuneable biodegradable polymeric nanoparticles by solvent displacement method using micro-engineered membranes fabricated by laser drilling and electroforming
}

\section{PLEASE CITE THE PUBLISHED VERSION}

http://dx.doi.org/10.1016/j.cej.2016.07.010

\section{PUBLISHER}

(C) Elsevier

\section{VERSION}

AM (Accepted Manuscript)

\section{PUBLISHER STATEMENT}

This work is made available according to the conditions of the Creative Commons Attribution-NonCommercialNoDerivatives 4.0 International (CC BY-NC-ND 4.0) licence. Full details of this licence are available at: https://creativecommons.org/licenses/by-nc-nd/4.0/

\section{LICENCE}

CC BY-NC-ND 4.0

\section{REPOSITORY RECORD}

Othman, Rahimah, Goran T. Vladisavljevic, Hamed Shahmohamadi, Zoltan K. Nagy, and R.G. Holdich. 2016. "Formation of Size-tuneable Biodegradable Polymeric Nanoparticles by Solvent Displacement Method Using Micro-engineered Membranes Fabricated by Laser Drilling and Electroforming". figshare.

https://hdl.handle.net/2134/21935. 
Graphical Abstract

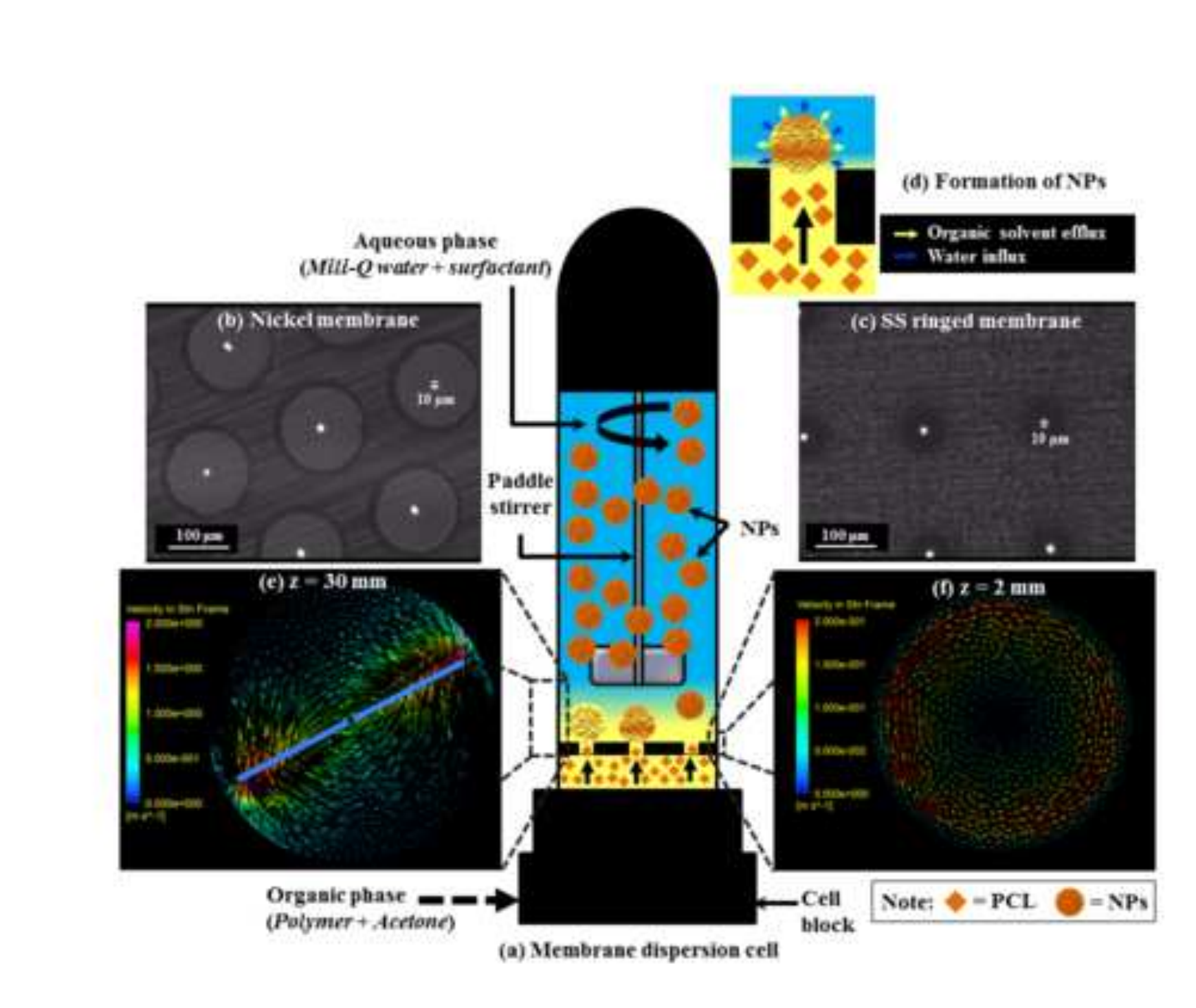

(a) Membrase dispersioa cell

(a) Menorane dispersiog cell

Graphical Abstract

.

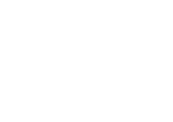




\section{Highlights}

- Size-tuneable NPs were formed by nanoprecipitation using microenginered membrane - A good micromixing favoured nucleation and led to a reduction in the particle size

- The minimum particle size was $159 \mathrm{~nm}$ with a polydispersity index (PDI) of 0.107

- Membrane with ringed operating area provided better performance than full membrane

- Laser-drilled pores led to smaller NPs than conical nickel electroformed pores 


\title{
Formation of size-tuneable biodegradable polymeric nanoparticles by solvent displacement method using micro-engineered membranes fabricated by laser drilling and electroforming
} Rahimah Othman ${ }^{\mathrm{a}, b^{*}}$, Goran T. Vladisavljevic ${ }^{\mathrm{a}^{*}}$, Hamed Shahmohamadi ${ }^{\mathrm{c}}$, Zoltan K. Nagy ${ }^{\mathrm{a}, \mathrm{d}}$, R.G. Holdich ${ }^{\mathrm{a}}$

${ }^{a}$ Department of Chemical Engineering, Loughborough University, Ashby Road, Loughborough, Leicestershire LE11 3TU, UK

${ }^{b}$ School of Bioprocess Engineering, Universiti Malaysia Perlis, Kompleks Pusat Pengajian Jejawi 3, 02600 Arau, Perlis, Malaysia

${ }^{c}$ Wolfson School of Mechanical and Manufacturing Engineering, Loughborough University, Loughborough LE11 3TU, United Kingdom

${ }^{d}$ School of Chemical Engineering, Purdue University, West Lafayette, IN 47907-2100, USA

*Corresponding author.Email address: ‥Othman@lboro.ac.uk, G.Vladisavljevic@1boro.ac.uk

\begin{abstract}
Biodegradable poly( $\varepsilon$-caprolactone) (PCL) drug-carrier nanoparticles (NPs) were produced by rapid membrane micromixing combined with nanoprecipitation in a stirred cell employing novel membrane dispersion. The organic phase composed of 0.1-0.6 wt\% PCL dissolved in tetrahydrofuran was injected into the aqueous phase (Mili-Q water or $0.2-1 \mathrm{wt} \%$ poly(vinyl alcohol) using two microfabricated membranes with different pore morphologies and spatial pore arrangements: ringed stainless steel membrane of reduced (annular) operating area with a square array of cylindrical laser-drilled pores and electroformed nickel membrane of full operating area with a hexagonal array of conical, funnel-shaped pores. The size of the NPs was precisely
\end{abstract}


controlled over a range of 159-394 $\mathrm{nm}$ by changing the aqueous-to-organic volumetric ratio, stirring rate, transmembrane flux, the polymer content in the organic phase, membrane type and pore size. The smallest and most uniform particles with a Z-average of $159 \mathrm{~nm}$ and a polydispersity index of $0.107 \pm 0.014$ were obtained using a $10 \mu \mathrm{m}$ pore-sized stainless steel membrane at the transmembrane flux of $140 \mathrm{~L} \mathrm{~m}^{-2} \mathrm{~h}^{-1}$, a stirring rate of $1,300 \mathrm{rpm}$, and an aqueous-to-organic phase volume ratio of $10 \mathrm{using} 1 \mathrm{~g} \mathrm{~L}^{-1} \mathrm{PCL}$ in the organic phase. The particle size decreased by increasing the stirring rate and the aqueous-to-organic volumetric ratio, and by decreasing the polymer concentration in the aqueous phase and the transmembrane flux. The existence of the peak shear stress within a transitional radius and a rapid decline of the shear stress away from the membrane surface were revealed by numerical modelling.

Keywords: Membrane dispersion cell; Computational fluid dynamics; Nanoprecipitation; Biodegradable polycaprolactone nanoparticles; microfabricated membrane; Micromixing.

\section{Introduction}

Biocompatible functional nanoparticles (NPs) for drug delivery have attracted growing interest in the past several decades [1-3]. These NPs should be able to preserve the drug from leakage while it is transported to a desired therapeutic site, so that the drug will not interact with non-targeted cells or tissues and cause side effects, and should be degraded or eliminated from the body after the drug has been released $[4,5]$. Polymeric NPs have been extensively studied as drug nanocarriers [6-9]. Synthetic aliphatic polyesters, such as poly-e-caprolactone (PCL) and polylactic acid (PLA), are highly desirable polymers for these applications due to their good mechanical properties, biodegradability, nontoxicity [10], and good compatibility with other 
polymers and inorganic nanofillers [11]. PCL and PLA have been approved by the U.S. Food and Drug Administration (FDA) for use as drug carriers. The PCL biodegradation product, 6hydroxycaproic acid, can be completely metabolised via the citric acid cycle, but the rate of degradation is very slow, which makes PCL ideally suited for long-term drug delivery.

Polymeric drug-loaded NPs can be fabricated using different techniques [12-14], including: (i) dispersion of preformed polymers (nanoprecipitation, emulsification-solvent evaporation/extraction/diffusion, salting-out, dialysis, spray drying, and supercritical fluid technology), (ii) polymerization of monomers, (iii) associative interactions among charged hydrophilic polymers (ionotropic gelation and complex coacervation), and (iv) particle replication in non-wetting templates (PRINT) [15]. Emulsification-solvent removal methods are associated with high energy consumption and often require the use of surfactants and toxic organic solvents. Nanoprecipitation is less energy demanding approach that does not require surfactants and usually involves less toxic (Class 2 and Class 3) organic solvents. The process is based on the interfacial deposition due to displacement of the polymer solvent by a non-solvent which must be miscible with the polymer solvent [16].

Membrane and microfluidic micromixing combined with nanoprecipitation have opened up new exciting opportunities for preparation of size-tuneable NPs [17-22]. Microfabricated membranes consisting of regular arrays of equally spaced pores have been increasingly used for the preparation of micro- and nanodispersions [23-28]. They enable uniform micromixing due to ordered pore array and uniform pore size, high flux through the membrane, and suppression of internal pore fouling due to thin and non-tortuous pores. Microfabricated pore arrays are similar to massively parallel $\mathrm{T}$ junctions, through which one fluid may be introduced into another at an overall much higher flow rate than is possible in individual channels [29]. The mixing rate can 
be enhanced by providing a controlled shear at the membrane surface using cross flow [30], stirring [23], flow pulsations [31], radially or axially oscillating membrane tube [32, 33], and rotating membrane [24]. However, the role of different pore arrangements, pore shapes and fabrication methods on the performance of microfabricated membrane in micromixing process has not yet been systematically investigated.

In this study, membrane micromixing/nanoprecipitation process has been investigated using two microfabricated membranes (stainless steel membrane with laser drilled pores and electroformed nickel membrane) with different pore patterns (square and hexagonal), pore shapes (conical and cylindrical) and operating areas (reduced ringed area and full circular area).

The main objectives were to evaluate the effect of pore morphology and operating parameters on the particle size distribution of PCL nanoparticles and to investigate velocity and shear profiles in the vicinity of the membrane surface using computational fluid dynamics (CFD). The mathematical model was solved using a commercial software package CFD package ANSYS FLUENT 14.5 in dimensional form.

\section{Materials and Methods}

\subsection{Chemicals}

Tetrahydrofuran (THF, HPLC grade, purity $\geq 99.9 \%$ ), poly( $\varepsilon$-caprolactone) $\left(\mathrm{PCL}, \mathrm{M}_{\mathrm{w}}=\right.$ $14,000 \mathrm{~g} \mathrm{~mol}^{-1}$ with a glass transition temperature of $60{ }^{\circ} \mathrm{C}$ ) and polyvinyl alcohol $\left(\mathrm{PVA}, \mathrm{M}_{\mathrm{w}}=\right.$ 13,000-23,000 $\mathrm{g} \mathrm{mol}^{-1}, 87-89 \%$ hydrolysed) were purchased from Sigma-Aldrich (Dorset, UK). PVA was used as a water soluble stabiliser to prevent agglomeration and imperfect surface formation of the NPs and THF was used as a solvent for PCL. The anti-solvent phase was pure 
water produced by reverse osmosis (Mili-Q ${ }^{\circledR}$, Millipore) or $0.2-1 \mathrm{wt} \%$ aqueous solution of PVA. All chemicals other than THF were of analytical grade.

\subsection{Membrane dispersion cell}

The NPs were prepared using a flat, disc-shaped membrane installed in a stirred cell shown in Fig. 1a. The cell and membranes were supplied by Micropore Technologies Ltd (Redcar, UK). The stirrer was driven by a 24 V DC motor (Instek model PR-3060) and its rotation speed was controlled between 200 and 1,300 rpm by the applied voltage. A nickel (Ni) membrane with an effective diameter of $3.3 \mathrm{~cm}$ and an operating area, $A_{m}$, of $8.55 \mathrm{~cm}^{2}$ had 24,690 hexagonally arranged pores with a diameter of 10, 20, and $40 \mu \mathrm{m}$, spaced apart at a constant distance of 200 $\mu \mathrm{m}$ (Fig. 1c and S2a-c). A ringed stainless steel (SS) membrane had the same dimensions and a reduced operating (active) area of $2.76 \mathrm{~cm}^{2}$ occupying space on the membrane surface between two concentric circles of radius $r_{1}=9 \mathrm{~mm}$ and $r_{2}=13 \mathrm{~mm}$ (Fig. S1b). SS membrane contained $\sim 6,912$ pores with a diameter of $10 \mu \mathrm{m}$ arranged in a square array with a pitch of $200 \mu \mathrm{m}$ (Fig. 1d). The number of pores was estimated from Eqs. (S1) and (S2) given in the supplement.

\subsection{Experimental set-up and preparation of polymeric NPs}

The cell was filled with $30-60 \mathrm{~mL}$ of mili-Q water or aqueous PVA solution and the stirring rate was adjusted to achieve the peak shear stress at the membrane surface between 0.7 and $14 \mathrm{~Pa}$. The organic phase was 0.1-0.6 wt\% PCL in THF and was injected through the membrane using a Cole-Parmer model 230 VAC syringe pump. The organic phase flow rate, $Q$ through the nickel membrane was $2-5 \mathrm{~mL} \mathrm{~min}^{-1}$ and thus, the transmembrane flux, $Q / A_{m}$, was 140-351 $\mathrm{L} \mathrm{m}^{-2} \mathrm{~h}^{-1}$. To achieve the same flux through the ringed membrane, the organic phase 
flow rate was reduced to $0.64-1.6 \mathrm{~mL} \mathrm{~min}^{-1}$, calculated from the equation: $Q_{R}=\left(A_{R} / A_{m}\right) Q$, where $A_{R}$ and $A_{m}$ are the operating areas of the ringed and whole membrane, respectively.

The experiments were run until a predetermined aqueous-to-organic phase volumetric ratio was achieved. The aqueous phase turned cloudy as soon as the organic phase was brought in contact with the aqueous phase due to rapid exchange of two solvents at the interface, i.e. THF diffused from the organic to the aqueous phase and water diffused in the opposite direction (Fig. 1b). THF was evaporated from the suspension in a vacuum oven at ambient temperature under a pressure of less than 10 Torr (Fistreem International Ltd, Loughborough, UK) until the smell of THF had disappeared $(\approx 30 \mathrm{~min})$. Each experiment was repeated at least three times.

After each experiment, the membrane was sonicated in THF for $30 \mathrm{~min}$ and then washed with Mili-Q water in an ultrasonic bath for $5 \mathrm{~min}$. The clean membrane was stored in acetone.

\subsection{Characterisation of the prepared NPs}

\subsubsection{Particle size analysis}

The particle size distribution was measured using a Delsa ${ }^{\mathrm{TM}}$ Nano HC Particle Analyser (Beckman Coulter, High Wycombe, UK) by dynamic light scattering (DLS) method, which measures the fluctuations in scattered light intensity as a function of time [34]. Smaller particles move faster than larger particles and therefore, the timescale of intensity fluctuations is shorter for smaller particles. A THF-free nanosuspension sample was transferred into a $4 \mathrm{~mL}$ disposable cuvette which was then placed into the instrument. The measurements were repeated thrice at a scattering angle of $165^{\circ}$ and a temperature of $25^{\circ} \mathrm{C}$ using CONTIN and Cumulants methods with a $120 \mathrm{~s}$ data acquisition time for each run. The cumulants analysis provides the $\mathrm{z}$-average size, which is the harmonic intensity averaged particle diameter and the polydispersity index (PDI), 
which is a dimensionless measure of the broadness of the size distribution. CONTIN algorithm imparts average peak diameter values from intensity size distribution [35].

\subsubsection{Zeta potential determination}

The zeta potential of the NPs was measured using a Malvern Instruments Zetasizer 3000 HAS particle size analyser. The measurements were repeated at least three times after sample dilution in water. The zeta potential was calculated from the electrophoretic mobility using the Helmholtz-Smoluchowski equation [36].

\subsubsection{Microscopic observations (TEM, FEG-SEM and Benchtop SEM)}

2-D micrographs of the prepared NPs were acquired using Transmission Electron Microscopy (TEM) and high resolution Field Emission Gun Scanning Electron Microscopy (FEG-SEM). In TEM analysis, samples were prepared by depositing a drop of suspension onto a carbon-coated copper mesh and left to dry before being observed by a JEOL JEM-2000FX analytical TEM operated at an accelerating voltage of $200 \mathrm{kV}$. The mesh was coated by dipping it into a suspension of carbon particles in deionised water.

3D SEM images of the fabricated NPs were acquired using a LEO model 1530 VP FEGSEM (LEO Elektronenmikroskopie GmbH, Oberkochen, Germany) with an integrated EDAX TEAM $^{\text {TM }}$ Pegasus EBSD/EDS (electron backscatter diffraction/energy dispersive X-ray spectrometry) system. The samples were placed onto conventional aluminium sample holders with a diameter of $\sim 1 \mathrm{~cm}$. The chamber was then evacuated to $\sim 0.5 \mathrm{~Pa}$ and the NPs images were taken using in-lens detector operating at an accelerating voltage of 5-10 $\mathrm{kV}$ and a working distance of 5-10 mm. FEG-SEM has the advantage over conventional SEM of providing higher 
resolution images due to a smaller distance of the electron beam, which gives higher signal-tonoise ratio, leading to improved spatial resolution especially for nanosize objects.

3D micrographs of cross-section of the micro-engineered membranes were obtained using a Hitachi model TM3030 benchtop SEM fitted with an Oxford Instruments Swift ED3000 Silicon drift detector (SDD) operated at $5-15 \mathrm{kV}$ voltage. A stage movement was controlled by a high resolution stepper motor with a $10 \mathrm{~nm}$ step size and a repositioning accuracy of $1 \mu \mathrm{m}$. The NPs were sputtered with gold to become electrically conductive and placed on a copper stub prior to the SEM imaging.

\section{Computational modeling}

The computational domain model geometry used to simulate fluid flow is shown in the supplementary material (Figure S2). A 3D simulation model is developed using the CFD package ANSYS FLUENT 14.5, constructed using ANSYS Design Modeller. Meshing preprocessor was used for the generation of the computational mesh. Considering the geometrical constraints, the fluid domain was meshed with tetrahedral cells while for the solid body (blades) hexahedral meshing scheme was used. The entire flow domain was then meshed using approximately one million cells. This was achieved by investigating the optimum number of cells that provide computational results which are independent of the number of cells and distribution of the computational grid. Hence, a grid independency test was performed. The governing equations used for modelling are provided in the supplementary material (see S3.1).

\section{Results and discussion}




\subsection{Effect of the aqueous-to-organic phase volumetric ratio}

In this series of experiments, $6 \mathrm{~mL}$ of the organic solution composed of $1 \mathrm{~g} \mathrm{~L}^{-1}$ of PCL in THF was injected at constant flux of $140 \mathrm{~L} \mathrm{~m}^{-2} \mathrm{~h}^{-1}$ through a $20-\mu \mathrm{m}$ Ni membrane into $9,18,27$, 42 , and $60 \mathrm{~mL}$ of water to achieve an aqueous-to-organic phase volumetric ratio of 1.5, 3.0, 4.5, 7.0 and 10.0, respectively. As shown in Fig. 2, the Z-average decreased with an increase in $V_{a q} / V_{o r}$. The size of a NP formed during solvent displacement is a result of the relative rates of nucleation, particle growth, and agglomeration. The promotion of particle growth over nucleation leads to fewer and larger particles. The rate of particle growth is:

$G=K_{g}\left(C_{P C L}-C_{P C L}^{*}\right)^{g}$

where $K_{g}$ is the growth constant, $C_{P C L}$ and $C_{P C L}^{*}$ are the local concentration and solubility of PCL in the solvent mixture, respectively, and $g$ is typically between 1 and 2 for organic systems [37]. The rate of nucleation is given by: $B=K_{b}\left(C_{P C L}-C_{P C L}^{*}\right)^{b}$, where $K_{b}$ is the nucleation constant, and $b$ lies between 5 and 10 . Since $b » g$, lower supersaturations, $C_{P C L}-C_{P C L}^{*}$, should promote particle growth over nucleation, leading to fewer and larger particles, whereas higher supersaturations will promote nucleation, resulting in a larger population of smaller particles. The organic phase was initially brought in contact with pure water and the rate of solvent exchange was very high due to high concentration driving force. However, since THF gradually accumulated in the aqueous phase, the rate of solvent exchange decreased leading to lower supersaturations. At smaller $V_{a q} / V_{o r}$ ratios, the concentration of THF in the aqueous phase increased at higher rate, which resulted in lower supersaturations and the formation of larger NPs. In addition, at higher THF concentrations in the aqueous phase, the rate of Ostwald ripening was higher due to greater solubility of PCL, which may also play a role in the formation 
of larger NPs at smaller $V_{a q} / V_{o r}$ ratios [38]. Agglomeration is another important factor in nanoprecipitation. Agglomerates form when growing NPs collide with each other and fuse together to form larger particles. Agglomeration is more pronounced at smaller $V_{a q} / V_{o r}$ values, because the collision frequency of particles is proportional to the second power of their number density.

Fig. 3 shows particle size distribution of the samples prepared at different aqueous-toorganic ratios and rotation speeds. Smaller and more uniform NPs were formed at higher aqueous-to-organic volumetric ratios. The same behaviour in membrane micromixing was observed by Du et al. [39] in the preparation of $\mathrm{SiO}_{2} \mathrm{NPs}$, Huang et al. [40] in the preparation of ZnO NPs and Laouini et al. [28, 41, 42] in the production of liposomes and polymeric micelles. The same trend was obtained when NPs were fabricated in microfluidic devices [11, 43, 44].

\subsection{Effect of agitation speed of aqueous phase}

As shown in Fig. 2, an increase in the agitation speed from 200 to 1,300 rpm caused a decrease in the Z-average, which can be attributed to the higher rate of solvent displacement, and hence higher supersaturation that can be achieved. Higher rotation speeds also helped to reduce agglomeration of freshly formed sticky particles near the membrane surface by providing higher mass transfer rates away from the membrane surface. The smallest Z-average $(196 \pm 5 \mathrm{~nm})$ and PDI $(0.128 \pm 0.012)$ values were obtained at the highest rotation speed of $1,300 \mathrm{rpm}$ and $V_{a q} / V_{o r}$ $=10$. On the other hand, the broadest particle size distribution with a PDI of $0.269 \pm 0.023$ and the largest Z-average value were obtained at the lowest agitation speed of $200 \mathrm{rpm}$ and $V_{a q} / V_{o r}$ $=1.5$. 


\subsection{Effect of transmembrane flux}

Fig. 4. shows the effect of flux on the particle size distribution, Z-average, and PDI at an agitation speed of 1,300 rpm, an aqueous-to-organic phase volumetric ratio of 10, and a PCL concentration in the organic phase of $1 \mathrm{~g} \mathrm{~L}^{-1}$. With an increase in flux from 140 to $351 \mathrm{~L} \mathrm{~m}^{-2} \mathrm{~h}^{-1}$, a significant broadening of the particle size distribution was observed with PDI rising from 0.128 to 0.164 . The increase in the organic phase flow rate leads to an increase in the rate of PCL mass transfer to the aqueous phase, which is given by: $C_{o} Q_{o r}$, where $C_{o}$ is the PCL concentration in the organic phase and $Q_{o r}$ is the organic phase flow rate. The influx rate of PCL has an opposite effect on particle size to stirring rate. The higher the PCL influx into the aqueous phase, the higher the concentration of particles near the membrane surface after polymer precipitation and hence, the higher the likelihood of the particle aggregation. Thus, the largest and least uniform particles were produced at the highest injection rate through the membrane. However, higher influx of PCL into the aqueous phase leads to higher supersaturation, which explains why the Zaverage only slightly increased from 196 to $200 \mathrm{~nm}$. Similar trends were observed for other NPs formed in membrane contactors [30, 41, 45, 46].

\subsection{Effect of polymer concentration}

The effect of PCL concentration in the organic phase on the Z-average and PDI at a rotation speed of $1,300 \mathrm{rpm}$ and a flux of $140 \mathrm{~L} \mathrm{~m}^{-2} \mathrm{~h}^{-1}$ is presented in Table 1. NPs with the largest Z-average $(347 \pm 11 \mathrm{~nm})$ and PDI $(0.243 \pm 0.023)$ values were obtained at $6 \mathrm{~g} \mathrm{~L}^{-1}$. As discussed above, the size of the NPs is dependent of the rate at which organic solvent diffuses into the aqueous phase and the rate at which the particle nuclei collide and fuse together. At 
higher polymer concentration in the organic phase, more nuclei per unit volume were formed and hence, particle aggregation was more pronounced. In addition, at higher PCL concentration the viscosity of the organic phase was higher which resulted in reduced diffusion rate of THF into the aqueous phase and reduced supersaturation. At low supersaturation, polymer nuclei grow faster than they nucleate resulting in larger NPs. Similar behaviour was observed by Khayata et al. [45] and Jaafar-Maalej et al. [18] who prepared PCL NPs and liposomes using SPG membrane. Laouini et al. [30] have prepared liposomes in a hollow fibre membrane contactor and found an increase in the mean vesicle size from 114 to $228 \mathrm{~nm}$ when the phospholipid concentration in the organic phase increased from 20 to $80 \mathrm{mg} \mathrm{mL}^{-1}$.

\subsection{Effect of membrane pore size}

The effect of the pore size of nickel membrane on the particle size at an agitation speed of $1,300 \mathrm{rpm}$, an aqueous-to-organic volumetric ratio of 10 , a flux of $140 \mathrm{~L} \mathrm{~m}^{-2} \mathrm{~h}^{-1}$ and a polymer concentration in the organic phase of $1 \mathrm{~g} \mathrm{~L}^{-1}$ is shown in Table 1 . In membrane emulsification, the mean droplet diameter, $\bar{d}_{d}$ in dripping regime is proportional to the mean pore diameter, $\bar{d}_{p}$ : $\bar{d}_{d}=c \bar{d}_{p}$, where $c$ is the proportionality constant that can vary between 2 and 10 [47]. In nanoprecipitation, the fundamental role of membrane is to provide good mixing of solvent with antisolvent: since nucleation is much faster than mixing, the generation of nuclei is governed by the rate of mixing step. Poor mixing results in low nucleation rates and a small population of large NPs, whereas good mixing results in high nucleation rates and a large population of small NPs. Smaller pores provide better mixing and thus smaller NPs, probably because the organic phase is split into thinner jets after passing through the membrane and the mixing time increases with the square of diffusion distance. On the other hand, smaller pore sizes can enhance 
membrane wetting, clogging and fouling, which can compromise the process. In this work, the Z-average decreased from 234 to $196 \mathrm{~nm}$ on reducing the pore size from 40 to $20 \mu \mathrm{m}$ at $V_{a q} / V_{o r}$ $=10$, revealing that the particle size in this pore size range was affected by the width of the jets formed at the pore outlets. However, the NPs formed using a $10-\mu \mathrm{m}$ membrane were larger than those formed using a $20-\mu \mathrm{m}$ membrane (Table 1), probably due to fouling that had occurred within the $10-\mu \mathrm{m}$ pores. As can be seen from the SEM image of the membrane cross section in Fig. $7 b$, the pores of a nickel membrane have a conical shape and may be more prone to fouling.

\subsection{Effect of polyvinyl alcohol (PVA)}

NPs can be stabilised by adding an amphipathic compound to the non-solvent that adsorb at the interface and provide a steric barrier against particle growth and aggregation. In this work, amphipathic polymer PVA was added to the aqueous phase in the amount between 0.1 and 1.0 wt $\%$ and the NPs were prepared under optimum conditions specified in the caption to Figure 5. The produced NPs were stored at ambient temperature over a period of 36 days to investigate the effect of PVA concentration on the long-term stability of the NPs.

Partially hydrolyzed PVA is a copolymer of poly(vinyl acetate) and poly (vinyl alcohol) with considerable block copolymer character [48]. The hydrophobic vinyl acetate part is preferentially attached to a hydrophobic surface of PCL, leaving the more hydrophilic vinyl alcohol segments dangling in the aqueous phase. At relatively low PVA concentrations $\left(\mathrm{C}_{\mathrm{PVA}} \approx\right.$ $0.1 \mathrm{wt} \%$ ), when surface coverage is much below the saturation, NPs were highly unstable due to bridging flocculation as a result of the tendency of PVA chains to adsorb onto the surface of two or more NPs simultaneously [38]. As $\mathrm{C}_{\mathrm{PVA}}$ increases to $0.2 \mathrm{wt} \%$ and the surface of the NPs 
became covered by PVA to at least $50 \%$ of the saturation coverage, steric stabilization dominated and the NPs were stable throughout the investigated period (Fig. 5a).

With a further increase in $\mathrm{C}_{\mathrm{PVA}}$ above $0.2 \mathrm{wt} \%$, nonadsorbed PVA molecules play an increasingly dominant role by introducing depletion attraction, which gives rise to a depletion flocculation. The magnitude of depletion attraction is proportional to the osmotic pressure in the aqueous phase, leading to increased particle instability between 0.2 and 1 wt $\%$ PVA (Fig. 5a). Further increase in $\mathrm{C}_{\mathrm{PVA}}$ above $1 \mathrm{wt} \%$ would stabilize the particles again, which is termed as depletion stabilization [49]. However, high PVA concentrations in the aqueous phase lead to large particle size, due to high viscosity of the aqueous phase so the PVA concentrations above 1 wt $\%$ were not investigated in this work.

The effect of PVA concentration in the aqueous phase on the zeta-potential of PCL NPs during storage is shown in Fig. 5b. The negative charge of NPs was probably due to acidic nature of hydrogen atoms attached to alpha carbon atoms of residual acetate groups in the PVA chains, which remained after the manufacture of PVA by the hydrolysis of polyvinyl acetate [50]. The zeta potential of the particles stabilized by $0.2 \mathrm{wt} \%$ PVA remained nearly unchanged within the storage period, revealing that the particle size was stable. The zeta potential has the highest negative value for $0.6-0.8 \mathrm{wt} \%$ PVA, but slightly decreased with time due to particle aggregation. It should be noted that PVA is a steric stabilizer, which means that low zeta potential values for $0.2 \mathrm{wt} \%$ PVA are not indication of poor particle stabilization.

\subsection{Effect of pore shape and membrane fabrication process}

The effect of membrane type on the average particle size, $Z_{\text {ave }}$ and particle size distribution is shown in Fig. 6. The smallest Z-average $(159 \pm 8 \mathrm{~nm})$ and most uniform particles 

membrane $\left(Z_{\text {ave }}=196 \pm 5 \mathrm{~nm}, \mathrm{PDI}=0.128 \pm 0.012\right)$ and $10 \mu \mathrm{m}-\mathrm{Ni}$ membrane $\left(Z_{\text {ave }}=218 \pm 13\right.$ $\mathrm{nm}, \mathrm{PDI}=0.160 \pm 0.019)$. Khayata et al. [45] produced vitamin E-loaded PCL NPs stabilized with $12.5 \%(\mathrm{w} / \mathrm{v})$ Tween $^{\circledR} 80$ using cross-flow SPG membrane with a pore size of $0.9 \mu \mathrm{m}$ and obtained the smallest particle size of $165 \mathrm{~nm}$ and the smallest PDI of 0.18. Different particle sizes obtained using the same pore size but different membrane type can be attributed to different pore shapes arising from the different techniques used for membrane fabrication.

Laser drilling of pores occurs through rapid melting and vaporisation of stainless steel due to absorption of energy from a focused laser beam. The melt is expelled from the hole once the gas pressure in a cavity overcomes surface tension forces. A re-solidified material (dross) that cannot be fully ejected from the hole due to high viscosity of the molten material was formed at the pore exits (Fig. 7b). Formation of dross can be minimised by using shorter wavelengths and pulse duration of laser beam. However, dross deposits did not have any adverse effect on the membrane performance, since the surface of the membrane on the laser exit side was in contact with incoming organic phase. Although the exit diameter of the pores was smaller than the inlet diameter, the pores were not significantly tapered, and thus the organic phase was injected from the pores at relatively high exit velocity contributing to the high mixing efficiency.

On the other hand, the pores of nickel membrane had a conical shape with a significant broadening toward the downstream side of the membrane (Fig. 7a). The reason for that is that during electroforming not only upward growth between the photoresist islands, but also lateral overgrowth over the photoresist islands occurred. Shallow cylindrical cavities on the upstream side of the membrane that can be seen in Fig. 7a are the footprints of these photoresist islands. If the nickel growth takes place exclusively between the photoresist islands, the pore diameter 
would be equal to the diameter of these islands $(\sim 135 \mu \mathrm{m})$. A smaller pore size $(10-40 \mu \mathrm{m})$ has been achieved by continuing to deposit $\mathrm{Ni}$ after the layer has reached the top of the resist pattern. The nickel then started to grow over the resist islands in the horizontal direction as well as in the vertical direction, as a result of which the pores became smaller and conical. Not all pores in Fig. $7 \mathrm{a}$ are conical, since the membrane was not cut through the centre of each pore. If the cut edge is not perpendicular to the membrane surface and does not go through the centre of each pore, the cross section of some pores will be cylindrical rather than conical and the pores will not extend across the entire cross section of the membrane. Conical pores were more prone to fouling and less efficient in mixing than straight pores due to lower exit velocity of the organic phase.

Another reason for the formation of smaller NPs using SS membrane is that the pores of this membrane were strategically arranged over a reduced annular area on the membrane surface corresponding to the maximum shear stress.

\subsection{Effect of membrane cleaning procedure}

Membrane cleaning was performed using the procedure described in Section 2.2 in order to restore the original contact angle and remove all residual polymer particles from the membrane surface. By keeping a low contact angle, the membrane was preferentially wetted by the aqueous phase, which prevents the organic phase from spreading over the membrane surface and ensures that tiny jets of the organic phase emerging from the pores penetrate directly into the aqueous phase. Figure S2 in the supplementary material shows optical micrographs of the downstream membrane surfaces before and after cleaning at different magnifications. The membranes were significantly fouled before cleaning with large particle aggregates deposited near the pore exits or inside the pores. After cleaning no particle could be seen on the membrane surfaces and all pores were unclogged, indicating that the cleaning procedure was appropriate. 


\subsection{TEM and SEM images of produced nanoparticles}

The FEG-SEM and TEM images of the NPs are shown in Fig. 8. As can be seen, PCL NPs have a spherical shape and relatively uniform size which is smaller than $200 \mu \mathrm{m}$. This particle size is in good correlation with the results obtained by static light scattering shown in Table 1 and Figure 4a. FEG-SEM provided a 3-D image, while TEM produced a flat (2-D) image of the synthesised PCL NPs.

\subsection{CFD simulation validation}

In this section, the results of numerical modelling are reported in order to validate the experimental results and to better understanding flow pattern in the cell. Fig. 9 shows flow parameters in two different cross sections located above the membrane at the heights of $30 \mathrm{~mm}$ (vicinity of the blades) and $2 \mathrm{~mm}$ (vicinity of the membrane). Fig. 9 (a-i) shows the flow velocity vectors in the vicinity of the blades. The velocity is increasing by getting closer to the tips of the blades and decreases progressively by moving away from the blades. On the blade surface the velocity is roughly equal to the blade's angular speed ( $\omega r)$. The pressure contours around the blades are presented in Fig. 9 (a-ii). The highest pressure is on the leading faces near the tips of the blades because of the highest drag force. The pressure around trailing faces of the blades is low because of high velocity of the flow. Fig.9 (a-iii) shows flow streamlines in the vicinity of the blades. Two nearly symmetrical vortices were formed at the trailing edge of the blades near the tip because of high velocity. Cavitation occurs when the suction pressure on the back of the blades reaches the vaporization pressure and the contours of cavitation-induced vapour volume fraction are shown in Fig.9 (a-iv). Fig.9 (b-i) illustrates velocity vectors of the flow in the plane near the membrane surface. The velocity vectors are parallel to the cell wall. The local velocity 
increases radially towards the wall until it reaches a maximum value and then suddenly drops to zero on the wall surface because of the no-slip boundary condition. The pressure distribution in the plane positioned $2 \mathrm{~mm}$ above the membrane surface is shown in Fig. 9 (b-ii). The pressure is high in the near-wall region and it is low in the centre.

Fig. 10 is a plot of the shear stress on different planes parallel to the membrane surface as a function of the radial distance from the axis of rotation at $1300 \mathrm{rpm}$. The shear stress on the membrane surface $(z=0)$ increases substantially towards the wall of the cell, reaches a peak value of $11.4 \mathrm{~Pa}$ at the transitional point, and then sharply declines to zero at the wall surface. The peak shear stress decreases exponentially with height and has a value of less than $2 \mathrm{~Pa}$ at the height of just $0.2 \mathrm{~mm}$ above the membrane surface. Therefore, the mixing rate is high on the membrane surface, where nucleation occurs and much smaller away from the membrane surface, which is useful because it limits the rate of particle aggregation.

Table 2 provides a comparison of numerical and analytical solutions for the transitional radius and peak shear stress on the membrane surface. The analytical solutions were derived using Eqs. (S18)-(S22) in the supplementary material. There is a good agreement between the numerical and analytical results with the peak shear stress on the membrane surface ranging between 11.4 and $14.0 \mathrm{~Pa}$ and the transitional radius between 10.7 and $13.3 \mathrm{~mm}$. These values for the transitional radius are within or very close the operating region of the ringed (SS) membrane. Because the pores of SS membrane were located only in the high shear region near the rotational radius, the average shear stress was higher for that membrane than for the nickel membrane. Therefore, ringed membrane should provide better micromixing performance than the nickel membrane, as confirmed by the experimental results. 


\section{Conclusions}

New process for the preparation of biodegradable polymeric nanoparticles has been developed, which employed dispersion of a polymer-containing amphiphilic organic solvent into the aqueous phase through a micro-engineered membrane combined with nanoprecipitation. The particle size distribution has been precisely tuned by the membrane pore size and shape, the location of active region of the membrane, aqueous-to-organic volumetric ratio, agitation speed, transmembrane flux and polymer concentration in the organic phase. The higher the aqueous-toorganic volumetric ratio, the higher the nucleation rate and the lower the rate of particle growth and aggregation, resulting in a larger population of smaller particles. At the same aqueous-toorganic volumetric ratio, the interdiffusion rate of two phases was higher at the higher agitation speed, resulting in higher supersaturation and smaller particle size. Increase in the flux through the membrane and polymer concentration in the organic phase led to domination of particle agglomeration over nucleation and formation of fewer and larger particles. Steric stabilization of PCL particles has been achieved by adding $0.2 \mathrm{wt} \%$ PVA to the aqueous phase, with the lower and higher PVA concentrations causing fast bridging and depletion flocculation, respectively.

The ringed stainless steel membrane with laser drilled pores was found to provide better performance than whole nickel membrane due to straight pores localized at the high shear stress region on the membrane surface. The numerical and analytical modelling revealed the existence of peak shear stress on the membrane surface at the transitional radius and rapid reduction in the shear stress by moving away from the membrane surface. Due to significant overgrowth of the resist islands during electroforming, nickel membrane had funnel-shaped pores, which led to less efficient mixing process probably due to lower exit velocity of the organic phase in the pores. 
The membrane cleaning procedure was highly efficient and enabled to restore fully the original membrane properties and remove all residual particles from the membrane surface.

The future work will be directed towards encapsulation of an immunosuppressive drug (rapamycin) within biodegradable polymer matrix using a ringed stainless steel membrane under the optimal operating conditions established in this study.

\section{Acknowledgements}

The authors acknowledge the financial support given for this work through the Ministry of Higher Education Malaysia and the technical assistance by Dr Zhaoxia Zhou and Dr Keith Yendall from the Department of Materials at Loughborough University for TEM and FEG-SEM analyses. The authors also acknowledge the financial support provided by the EPSRC grant EP/HO29923/1 and the European Research Council grant [280106-CrySys].

\section{Appendix A. Supplementary data}

Supplementary data associated with this article can be found, in the online version, at http://dx.doi.org//xxxxxxx

\section{References}

[1] J. Zhang, C.Q. Lan, M. Post, B. Simard, Y. Deslandes, T.H. Hsieh, Design of nanoparticles as drug carriers for cancer therapy, Cancer Genomics Proteomics 3 (2006) 147-157.

[2] G.M. Barratt, Therapeutic applications of colloidal drug carriers, Pharm. Sci. Tech. Today 3 (2000) 163-171.

[3] M.V. Chaubal, Application of drug delivery technologies in lead candidate selection and optimization, Drug Discov. Today 9 (2004) 603-609. 
[4] W.H. De Jong, P.JA. Borm, Drug delivery and nanoparticles: applications and hazards, Int. J. Nanomedicine 3 (2008) 133-149.

[5] P.K. Ghosh, Hydrophilic polymeric nanoparticles as drug carriers, Indian J. Biochem. Biophys. 37 (2000) 273-282.

[6] P. Legrand, S. Lesieur, A. Bochot, R. Gref, W. Raatjes, G. Barratt, C. Vauthier, Influence of polymer behaviour in organic solution on the production of polylactide nanoparticles by nanoprecipitation, Int. J. Pharm. 344 (2007) 33-43.

[7] K. Letchford, H. Burt, A review of the formation and classification of amphiphilic block copolymer nanoparticulate structures: micelles, nanospheres, nanocapsules and polymersomes, Eur. J. Pharm. Biopharm. 65 (2007) 259-269.

[8] D. Moinard-Checot, Y. Chevalier, S. Briançon, H. Fessi, S. Guinebretière, Nanoparticles for drug delivery: Review of the formulation and process difficulties illustrated by the emulsion-diffusion process, J. Nanosci. Nanotechnol. 6 (2006) 2664-2681.

[9] D. Quintanar-Guerrero, E. Allémann, H. Fessi, Preparation techniques and mechanisms of formation of biodegradable nanoparticles from preformed polymers, Drug Dev. Ind. Pharm. 24 (1998) 1113-1128.

[10] V.R. Sinha, K. Bansal, R. Kaushik, R. Kumria, A. Trehanet, Poly- $\epsilon$-caprolactone microspheres and nanospheres: an overview, Int. J. Pharm. 278 (2004) 1-23.

[11] R. Othman, G.T. Vladisavljević, N.L. Thomas, Z.K. Nagy, Fabrication of composite poly(D,L-lactide)/montmorillonite nanoparticles for controlled delivery of acetaminophen by solvent-displacement method using glass capillary microfluidics, Colloids Surf., B 141 (2016) 187-195. 
[12] C.P. Reis, R.J. Neufeld, A.J. Ribeiro, F. Veiga, Nanoencapsulation I. Methods for preparation of drug-loaded polymeric nanoparticles, Nanomedicine 2 (2006) 8-21.

[13] J.P. Rao, K.E. Geckeler, Polymer nanoparticles: preparation techniques and size-control parameters, Prog. Polym. Sci. 36 (2011) 887-913.

[14] B.V.N. Nagavarma, K.S.Y. Hemant, A. Ayaz, L.S. Vasudha, H.G. Shivakumar, Different techniques for preparation of polymeric nanoparticles - a review, Asian J. Pharm. Sci. 5 (2012) 16-23.

[15] J.P. Rolland, B.W. Maynor, L.E. Euliss, A.E. Exner, M. Ginger, G.M. Denison, J.M. DeSimone, Direct fabrication and harvesting of monodisperse, shape-specific nanobiomaterials, J. Am. Chem. Soc. 127 (2005) 10096-10100.

[16] H. Fessi, F. Puisieux, J.P. Devissaguet, N. Ammoury, S. Benita, Nanocapsule formation by interfacial polymer deposition following solvent displacement, Int. J. Pharm. 55 (1989) R1-R4.

[17] T.T. Pham, C. Jaafar-Maalej, C. Charcosset, H. Fessi, Liposome and niosome preparation using a membrane contactor for scale-up, Colloids Surf., B 94 (2012) 15-21.

[18] C. Jaafar-Maalej, C. Charcosset, H. Fessi, A new method for liposome preparation using a membrane contactor, J. Liposome Res. 21 (2011) 213-220.

[19] G. Chen, G.S. Luo, J.H. Xu, J.D. Wang, Membrane dispersion precipitation method to prepare nanopartials, Powder Technol. 139 (2004) 180-185.

[20] C. Charcosset, H. Fessi, A new process for drug loaded nanocapsules preparation using a membrane contactor, Drug Dev. Ind. Pharm. 31 (2005) 987-992.

[21] Z.Q. Jia, Z.Z. Liu, Membrane-dispersion reactor in homogeneous liquid process, J. Chem. Technol. Biotechnol. 88 (2013) 163-168. 
[22] G.T. Vladisavljević, A. Laouini, C. Charcosset, H. Fessi, H.C.H. Bandulasena, R.G. Holdich, Production of liposomes using microengineered membrane and co-flow microfluidic device, Colloids Surf., A 458 (2014) 168-177.

[23] S.R. Kosvintsev, G. Gasparini, R.G. Holdich, I.W. Cumming, M.T. Stillwell, Liquid-liquid membrane dispersion in a stirred cell with and without controlled shear, Ind. Eng. Chem. Res. 44 (2005) 9323-9330.

[24] G.T. Vladisavljević, R.A. Williams, Manufacture of large uniform droplets using rotating membrane emulsification, J. Colloid Interface Sci. 299 (2006) 396-402.

[25] I. Kobayashi, S. Mukataka, M. Nakajima, Effects of type and physical properties of oil phase on oil-in-water emulsion droplet formation in straight-through microchannel emulsification, experimental and CFD studies, Langmuir 21 (2005) 5722-5730.

[26] A. Nazir, K. Schroën, R. Boom, High-throughput premix membrane emulsification using nickel sieves having straight-through pores, J. Memb. Sci. 383 (2011) 116-123.

[27] A. Imbrogno, M.M. Dragosavac, E. Piacentini, G.T. Vladisavljević, R.G. Holdich, L. Giorno, Polycaprolactone multicore-matrix particle for the simultaneous encapsulation of hydrophilic and hydrophobic compounds produced by membrane emulsification and solvent diffusion processes, Colloids Surf., B 135 (2015) 116-125.

[28] A. Laouini, K.P. Koutroumanis, C. Charcosset, S. Georgiadou, H. Fessi, R.G. Holdich, G.T. Vladisavljević, pH-sensitive micelles for targeted drug delivery prepared using a novel membrane contactor method. ACS Appl. Mater. Interfaces 5 (2013) 8939-8947.

[29] G.T. Vladisavljević, I. Kobayashi, M. Nakajima, Production of uniform droplets using membrane, microchannel and microfluidic emulsification devices, Microfluid. Nanofluidics 13 (2012) 151-178. 
[30] A. Laouini, C. Jaafar-Maalej, S. Sfar, C. Charcosset, H. Fessi, Liposome preparation using a hollow fiber membrane contactor-application to spironolactone encapsulation, Int. J. Pharm. 415 (2011) 53-61.

[31] R.G. Holdich, M. Dragosavac, G.T. Vladisavljević, E. Piacentini, Continuous membrane emulsification with pulsed (oscillatory) flow, Ind. Eng. Chem. Res. 52 (2013) 507-515.

[32] P.S. Silva, M.M. Dragosavac, G.T. Vladisavljević, H.C.H. Bandulasena, R.G. Holdich, Azimuthally oscillating membrane emulsification for controlled droplet production, AIChE J. 61 (2015) 3607-3615.

[33] R.G. Holdich, M.M. Dragosavac, G.T. Vladisavljević, S.R. Kosvintsev, Membrane emulsification with oscillating and stationary membranes, Ind. Eng. Chem. Res. 49 (2010) $3810-3817$.

[34] D.N. Submicron, User's Manual: Delsa ${ }^{\mathrm{TM}}$ Nano Subricon Particle Size and Zeta Potential, Beckman Coulter Ireland Inc., Ireland, 2011.

[35] British Standards Institution. Methods for determination of particle size distribution - Part 8: Photon correlation spectroscopy, 1997, pp. BSI 11-1998.

[36] R.J. Hunter, B.R. Midmore, H. Zhang, Zeta potential of highly charged thin double-layer systems, J. Colloid Interface Sci. 237 (2001) 147-149.

[37] H. Zhao, J.X. Wang, Q.A. Wang, J.F. Chen, J. Yun, Controlled liquid antisolvent precipitation of hydrophobic pharmaceutical nanoparticles in a microchannel reactor, Ind. Eng. Chem. Res. 46 (2007) 8229-8235.

[38] J.W. Seo, K.J. Kim, S.H. Kim, K.M. Hwang, S.H. Seok, E.S. Park, Effect of process parameters on formation and aggregation of nanoparticles prepared with a Shirasu Porous Glass Membrane, Chem. Pharm. Bull. 63 (2015) 792-798. 
[39] L. Du, J. Tan, K. Wang, Y. Lu, G. Luo, Controllable preparation of $\mathrm{SiO}_{2}$ nanoparticles using a microfiltration membrane dispersion microreactor, Ind. Eng. Chem. Res. 50 (2011) $8536-8541$.

[40] C. Huang, Y. Wang, G. Luo, Preparation of highly dispersed and small-sized $\mathrm{ZnO}$ nanoparticles in a membrane dispersion microreactor and their photocatalytic degradation, Ind. Eng. Chem. Res. 52 (2013) 5683-5690.

[41] A. Laouini, C. Charcosset, H. Fessi, R.G. Holdich, G.T. Vladisavljević, Preparation of liposomes: a novel application of microengineered membranes - investigation of the process parameters and application to the encapsulation of vitamin E, RSC Adv. 3 (2013) 4985-4994.

[42] A. Laouini, C. Charcosset, H. Fessi, R.G. Holdich, G.T. Vladisavljević, Preparation of liposomes: a novel application of microengineered membranes - from laboratory scale to large scale, Colloids Surf., B 112 (2013) 272-278.

[43] R. Othman, G.T. Vladisavljević, H.H.C. Bandulasena, Z.K. Nagy, Production of polymeric nanoparticles by micromixing in a co-flow microfluidic glass capillary device, Chem. Eng. J. 280 (2015) 316-329.

[44] R. Othman, G.T. Vladisavljević, Z.K. Nagy, Preparation of biodegradable polymeric nanoparticles for pharmaceutical applications using glass capillary microfluidics, Chem. Eng. Sci. 137 (2015) 119-130.

[45] N. Khayata, W. Abdelwahed, M.F. Chehna, C. Charcosset, H. Fessi, Preparation of vitamin E loaded nanocapsules by the nanoprecipitation method: from laboratory scale to large scale using a membrane contactor, Int. J. Pharm. 423 (2012) 419-427. 
[46] N. Sheibat-Othman, T. Tim Burne, C. Charcosset, H. Fessi, Preparation of pH-sensitive particles by membrane contactor, Colloids Surf., A 315 (2008) 13-22.

[47] C. Charcosset, I. Limayem, H. Fessi, The membrane emulsification process - a review, J. Chem. Technol. Biotechnol. 79 (2004) 209-218.

[48] S.K. Sahoo, J. Panyam, S. Prabha, V. Labhasetwar, Residual polyvinyl alcohol associated with poly (D,L-lactide-co-glycolide) nanoparticles affects their physical properties and cellular uptake, J. Control Release 82 (2002) 105-114.

[49] S. Kim, K. Hyun, J.Y. Moon, C. Clasen, K.H. Ahn, Depletion stabilization in nanoparticle-polymer suspensions: multi-length-scale analysis of microstructure, Langmuir 31 ( 2015) 1892-1900.

[50] M. Wiśniewska, The temperature effect on electrokinetic properties of the silica-polyvinyl alcohol (PVA) system, Colloid Polym. Sci. 289 (2011) 341-344.

[51] S. Nagata, Mixing: Principles and Applications, Kodansha Ltd., Tokyo, Japan, 1975. 
Table 1. The effect of the PCL concentration, the membrane pore size and the aqueous-toorganic volumetric ratio on the Z-average and polydispersity index, PDI. The agitation speed was $1,300 \mathrm{rpm}$ and the transmembrane flux through a nickel membrane was $140 \mathrm{~L} \mathrm{~m}^{-2} \mathrm{~h}^{-1}$.

\begin{tabular}{ccccc}
\hline $\begin{array}{c}\text { PCL concentration } \\
\left(\mathrm{mg} \mathrm{mL}^{-1}\right)\end{array}$ & $\begin{array}{c}\text { Membrane pore } \\
\text { size }(\mu \mathrm{m})\end{array}$ & $\begin{array}{c}\text { Volumetric } \\
\text { ratio, } V_{a q} / V_{\text {or }}\end{array}$ & $\begin{array}{c}{ }^{a} \text { Mean NP size, } \\
Z_{\text {ave }}(\mathrm{nm})\end{array}$ & $\begin{array}{c}{ }^{a} \text { Polydispersity } \\
\text { index, PDI }\end{array}$ \\
\hline 1 & 20 & 10 & $196 \pm 5$ & $0.128 \pm 0.01$ \\
3 & 20 & 10 & $278 \pm 7$ & $0.221 \pm 0.01$ \\
6 & 20 & 10 & $347 \pm 11$ & $0.242 \pm 0.02$ \\
1 & 10 & 10 & $218 \pm 13$ & $0.160 \pm 0.04$ \\
1 & 10 & 7 & $234 \pm 16$ & $0.177 \pm 0.05$ \\
1 & 10 & 4.5 & $242 \pm 9$ & $0.198 \pm 0.04$ \\
1 & 10 & 3 & $277 \pm 5$ & $0.219 \pm 0.01$ \\
1 & 10 & 1.5 & $331 \pm 16$ & $0.245 \pm 0.04$ \\
1 & 20 & 7 & $215 \pm 5$ & $0.144 \pm 0.01$ \\
1 & 20 & 4.5 & $225 \pm 2$ & $0.162 \pm 0.01$ \\
1 & 20 & 3 & $235 \pm 3$ & $0.174 \pm 0.01$ \\
1 & 20 & 1.5 & $274 \pm 1$ & $0.186 \pm 0.01$ \\
1 & 40 & 10 & $234 \pm 20$ & $0.218 \pm 0.04$ \\
1 & 40 & 7 & $254 \pm 11$ & $0.244 \pm 0.02$ \\
1 & 40 & 4.5 & $329 \pm 8$ & $0.270 \pm 0.02$ \\
1 & 40 & 3 & $382 \pm 13$ & $0.327 \pm 0.03$ \\
1 & 40 & 1.5 & $464 \pm 11$ & $0.389 \pm 0.04$ \\
\hline & & &
\end{tabular}

${ }^{a}$ : Each value is a mean of three repeated measurements. The error bars are standard deviations. 
Table 2. Comparison of the numerical and analytical solutions for the transitional radius and the peak shear stress on the membrane surface at $1300 \mathrm{rpm}$ (angular velocity, $\omega=136 \mathrm{rad} \mathrm{s}^{-1}$ ). The shear stress at the membrane surface reaches a maximum value at the transitional radius.

\begin{tabular}{lcc}
\multicolumn{1}{c}{ Parameter } & CFD results & \multicolumn{1}{c}{$\begin{array}{c}\text { Analytical results } \\
\text { (Nagata [51]) }\end{array}$} \\
\hline $\begin{array}{l}\text { Transitional radius, } r_{\text {trans }} \\
(\mathrm{mm})\end{array}$ & 13.3 & 10.7 \\
$\begin{array}{l}\text { Maximum shear stress, } \\
\tau_{\max }(\mathrm{Pa})\end{array}$ & 11.4 & 14.0 \\
$\begin{array}{l}\text { Average shear stress, } \tau \\
(\mathrm{Pa})\end{array}$ & - & $\begin{array}{l}\text { 7.03 (for whole membrane) and 13.1 (for } \\
\text { ringed membrane) }\end{array}$ \\
\hline
\end{tabular}




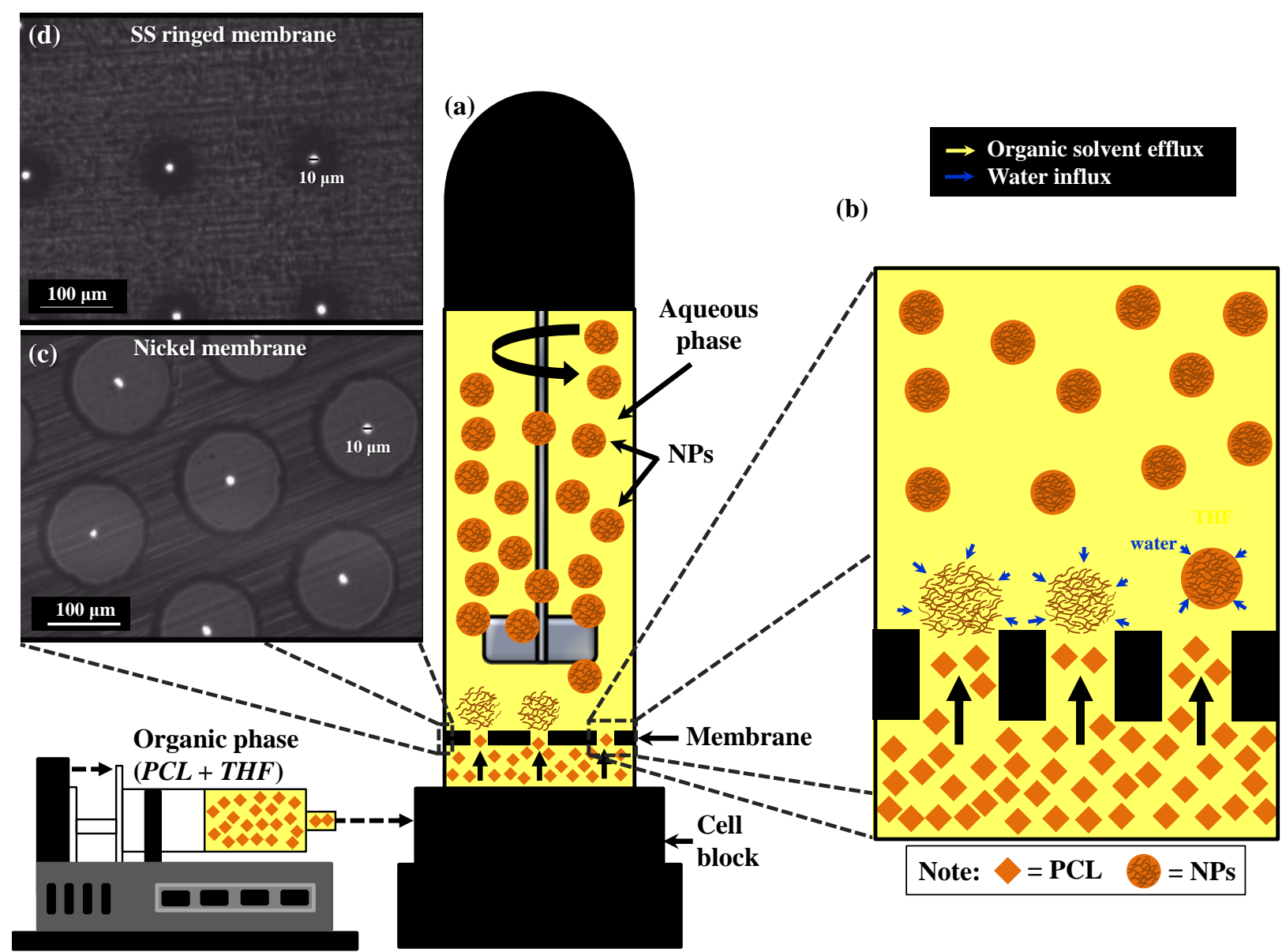

Fig. 1. (a) A schematic diagram of the membrane dispersion cell with a paddle stirrer fitted above a micro-engineered membrane; (b) Formation of NPs by rapid solvent displacement above the membrane surface $($ yellow colour $=$ solvent); $(c)$ Optical micrograph of a $10 \mu \mathrm{m}$ pore-sized nickel membrane; (d) Optical micrograph of a $10 \mu \mathrm{m}$ pore-sized stainless steel membrane. 


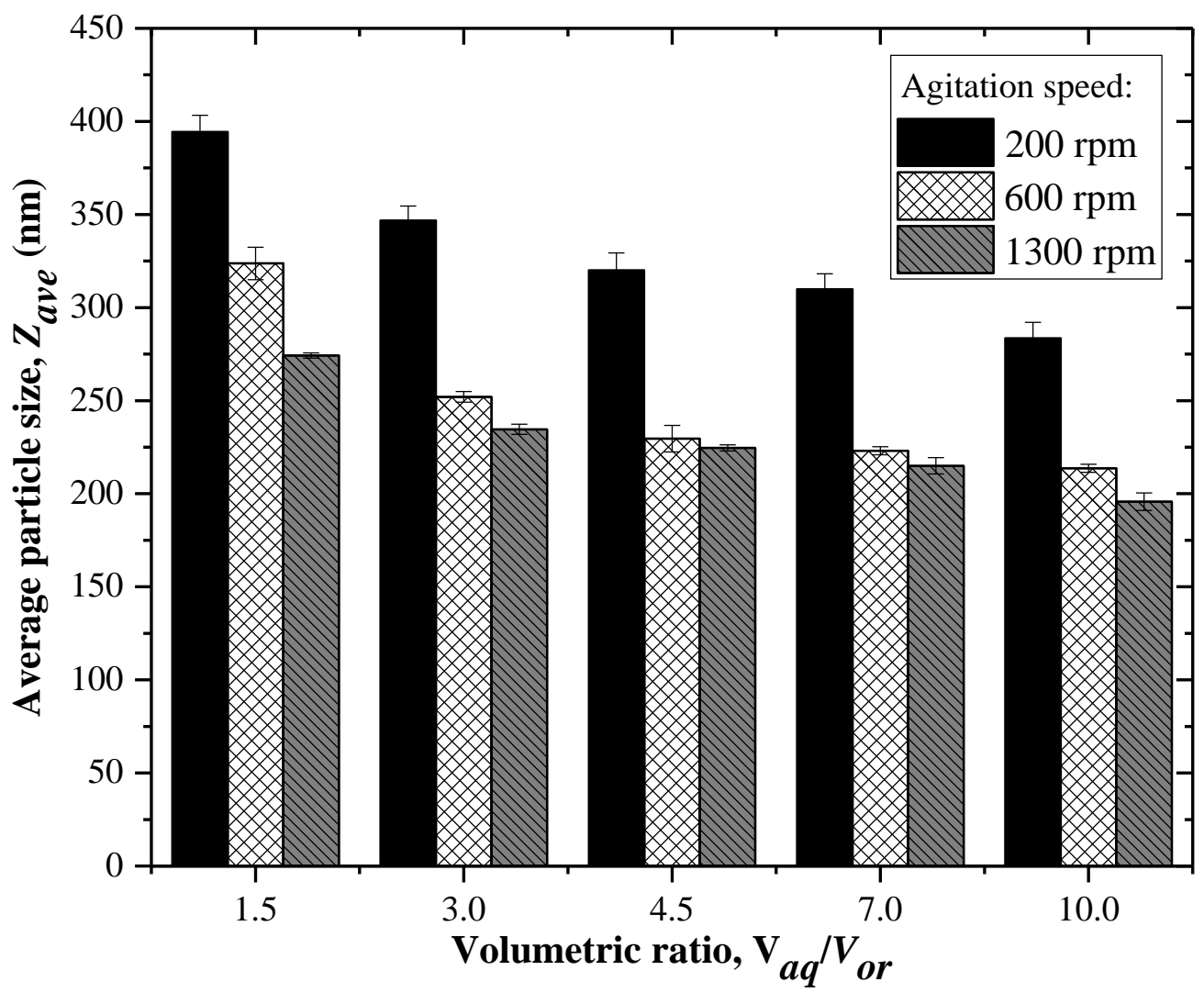

Fig. 2. The average particle size, $Z_{\text {ave }}$ of PCL NPs produced at different aqueous-to-organic phase volumetric ratios and different agitation speeds using a $20-\mu \mathrm{m}$ Ni membrane. The PCL concentration in the organic phase is $1 \mathrm{~g} \mathrm{~L}^{-1}$ and the transmembrane flux is $140 \mathrm{~L} \mathrm{~m}^{-2} \mathrm{~h}^{-1}$. 


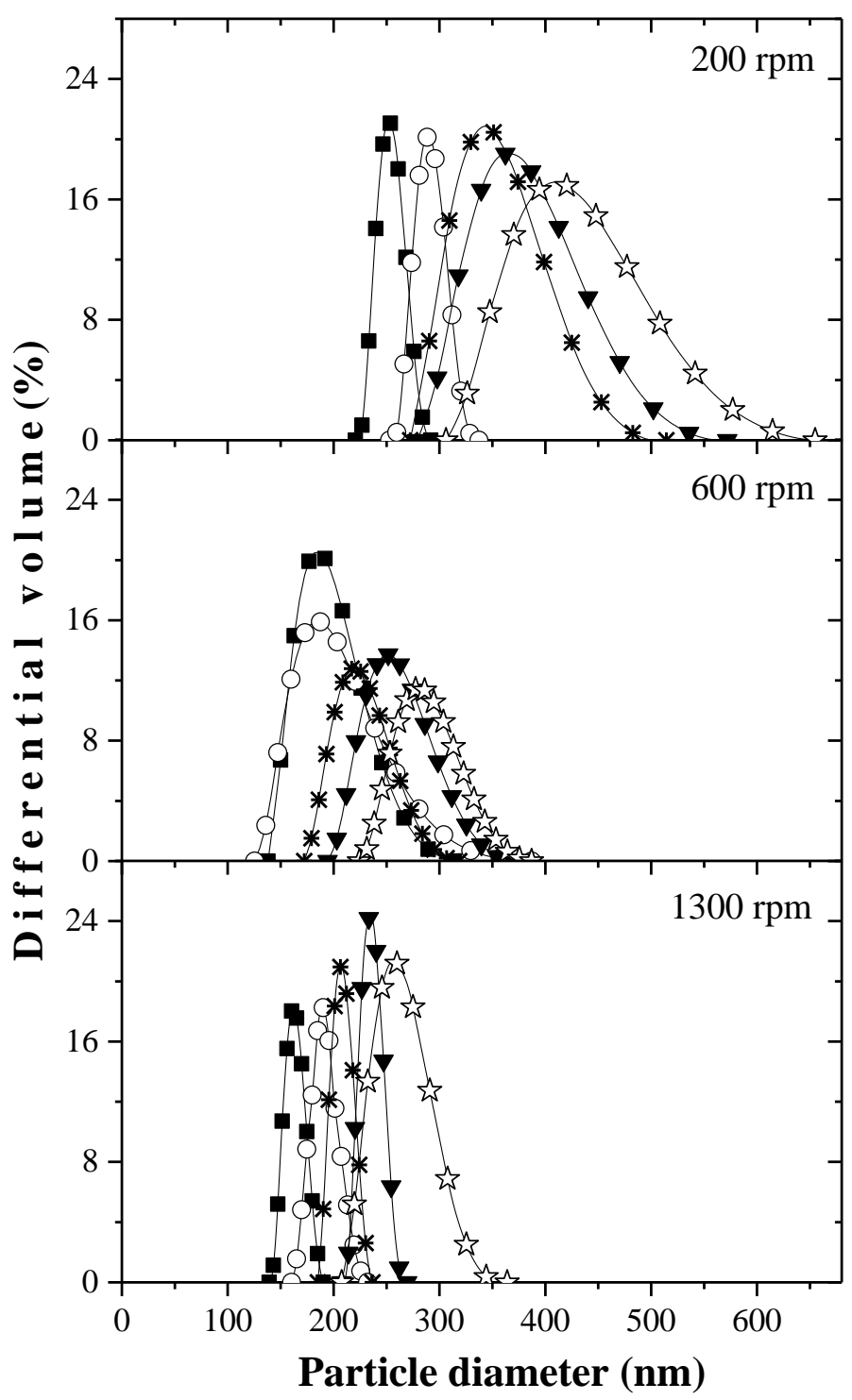

$$
\begin{aligned}
& \square V_{a q} / V_{o r}=10.0 \multimap-V_{a q} / V_{o r}=7.0 \multimap-V_{a q} / V_{o r}=4.5 \\
& \nabla V_{a q} / V_{o r}=3.0 \multimap-V_{a q} / V_{o r}=1.5
\end{aligned}
$$

Fig. 3. The volume-weighted particle size distribution of PCL NPs as a function of aqueous-toorganic phase volumetric ratio. The pore size of Ni membrane is $20 \mu \mathrm{m}$, the transmembrane flux is $140 \mathrm{~L} \mathrm{~m}^{-2} \mathrm{~h}^{-1}$ and the PCL concentration in the organic phase is $1 \mathrm{~g} \mathrm{~L}^{-1}$. 

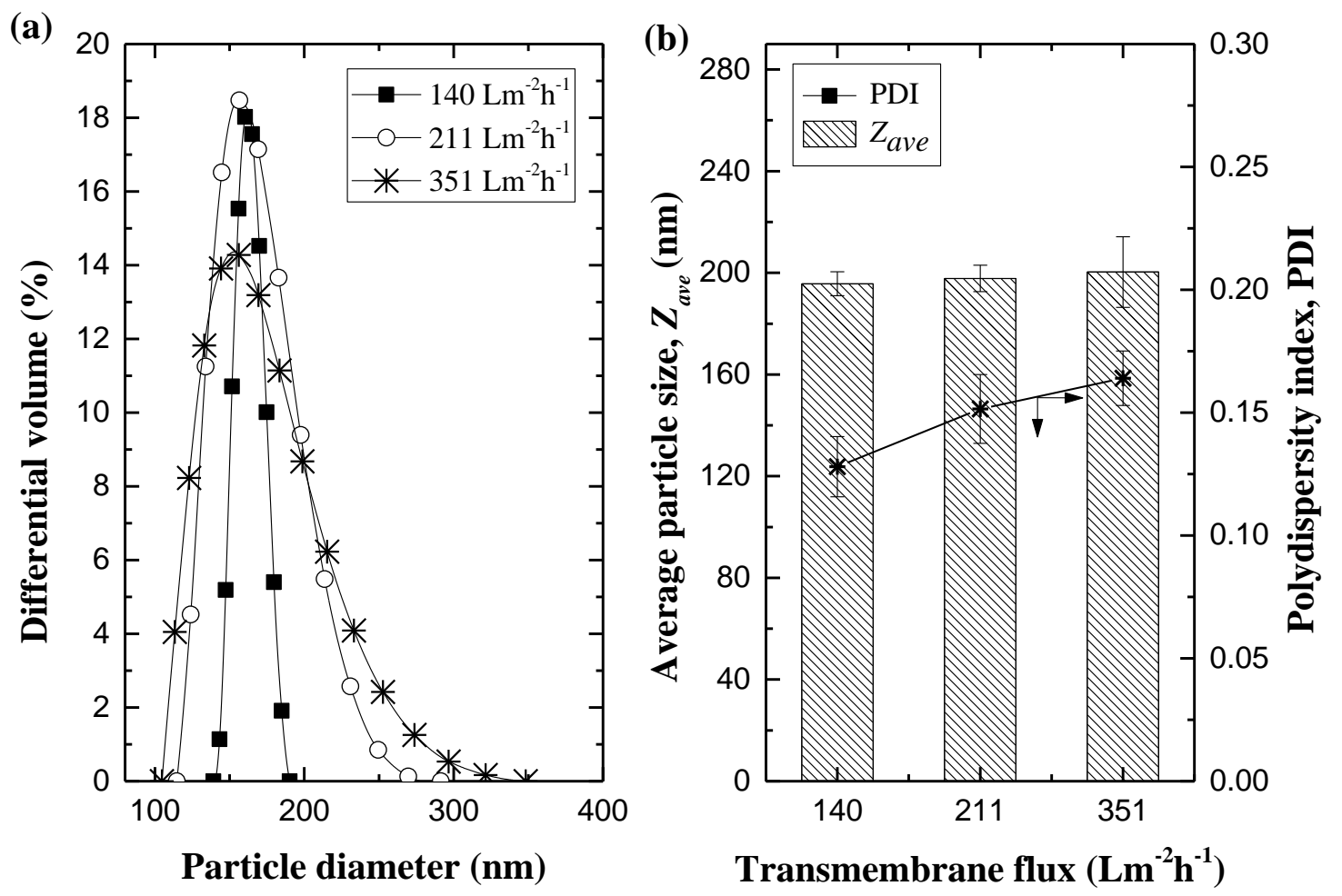

Fig. 4. The effect of transmembrane flux through a $20-\mu \mathrm{m}$ nickel membrane on: (a) the volumeweighted particle size distribution, and (b) the Z-average and polydispersity index, PDI. The agitation speed was $1,300 \mathrm{rpm}$, the aqueous-to-organic phase volumetric ratio was 10 , the PCL concentration in the organic phase was $1 \mathrm{~g} \mathrm{~L}^{-1}$. 
(a)

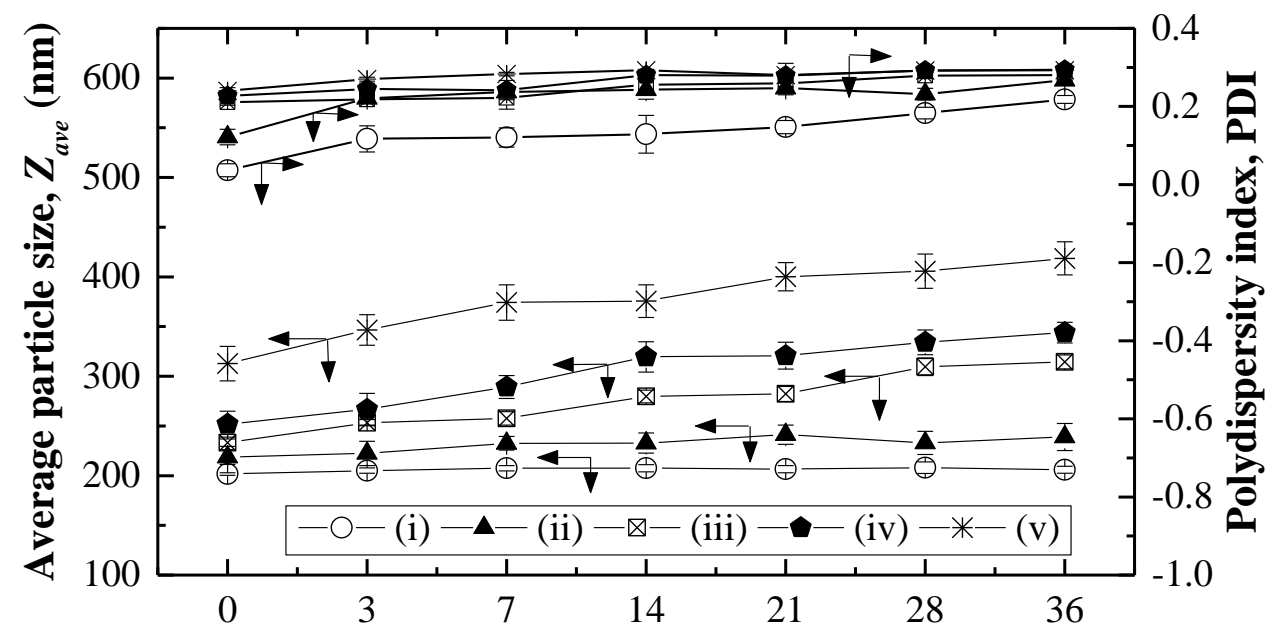

(b)

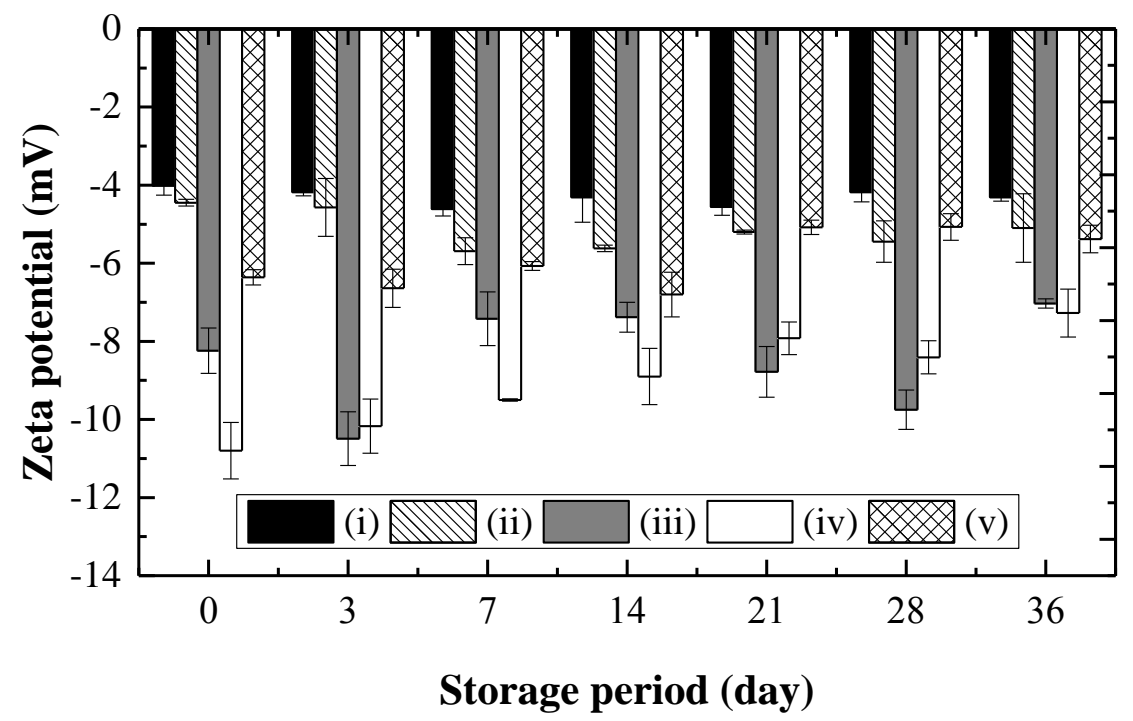

Fig. 5. Effect of concentration of PVA in the aqueous phase on the storage stability of NPs at ambient temperature: (i) $0.2 \mathrm{wt} \%$ PVA, (ii) $0.4 \mathrm{wt} \%$ PVA, (iii) $0.6 \mathrm{wt} \%$ PVA, (iv) $0.8 \mathrm{wt} \%$ PVA and (v) $1.0 \mathrm{wt} \%$ PVA. The PCL NPs were prepared at a transmembrane flux of $140 \mathrm{~L} \mathrm{~m}^{-2} \mathrm{~h}^{-1}$, a stirring rate of 1,300 rpm, and an aqueous-to-organic phase volumetric ratio of $10 \mathrm{using}$ a $20 \mu \mathrm{m}$ pore-sized nickel membrane. The PCL concentration in the organic phase was $1 \mathrm{~g} \mathrm{~L}^{-1}$. 
(a)

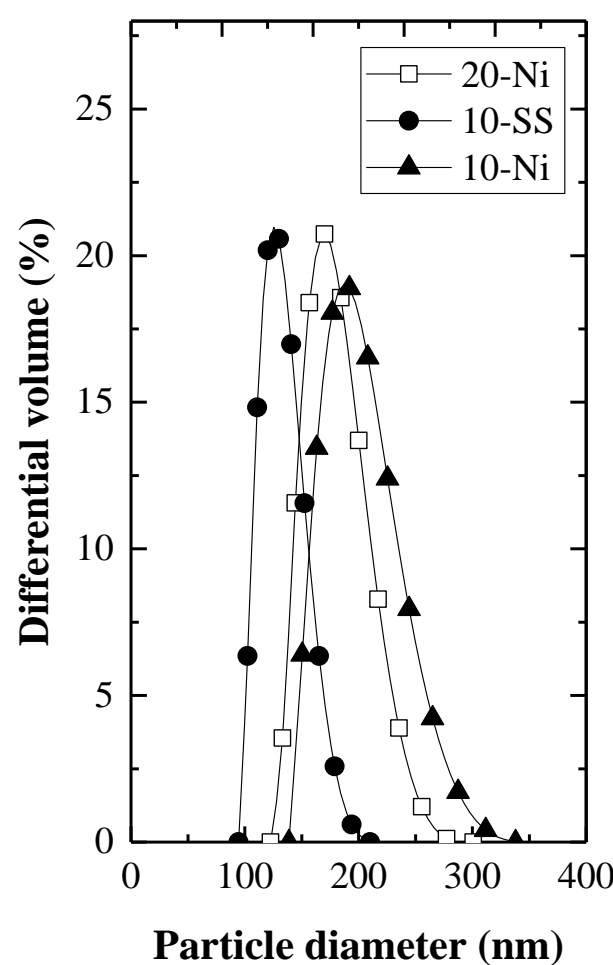

(b)

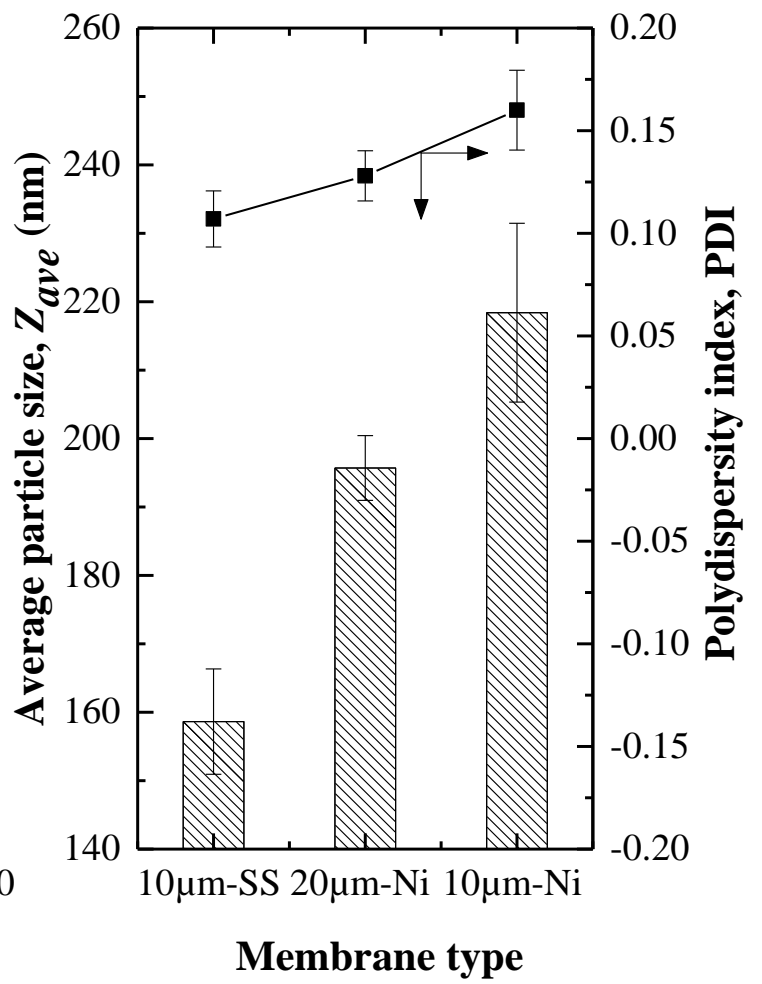

Fig. 6. Effect of membrane type and pore size on: (a) volume-weighted particle size distribution, (b) average particle size, $Z_{\text {ave }}(\mathrm{nm})$. The NPs were prepared at a transmembrane flux of $140 \mathrm{~L} \mathrm{~m}^{-2}$ $\mathrm{h}^{-1}$, a stirring rate of 1,300 rpm, and an aqueous-to-organic phase volumetric ratio of 10 . The PCL concentration in the organic phase was $1 \mathrm{~g} \mathrm{~L}^{-1}$ and no stabilizer was used. 


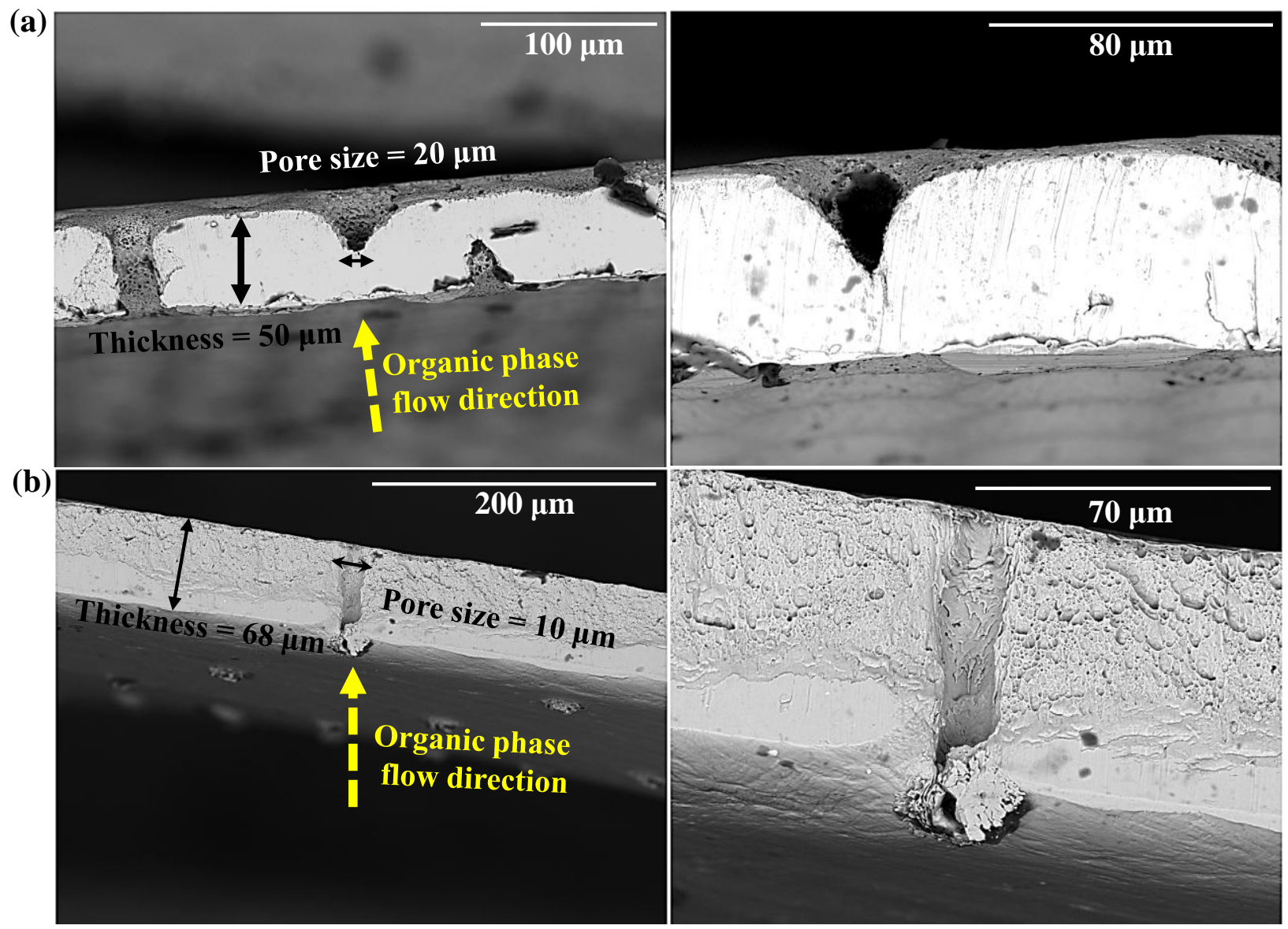

Fig. 7. Scanning electron microscope (SEM) images of membrane cross sections at various magnifications: (a) whole nickel (Ni) membrane; (b) stainless steel (SS) ringed membrane. 

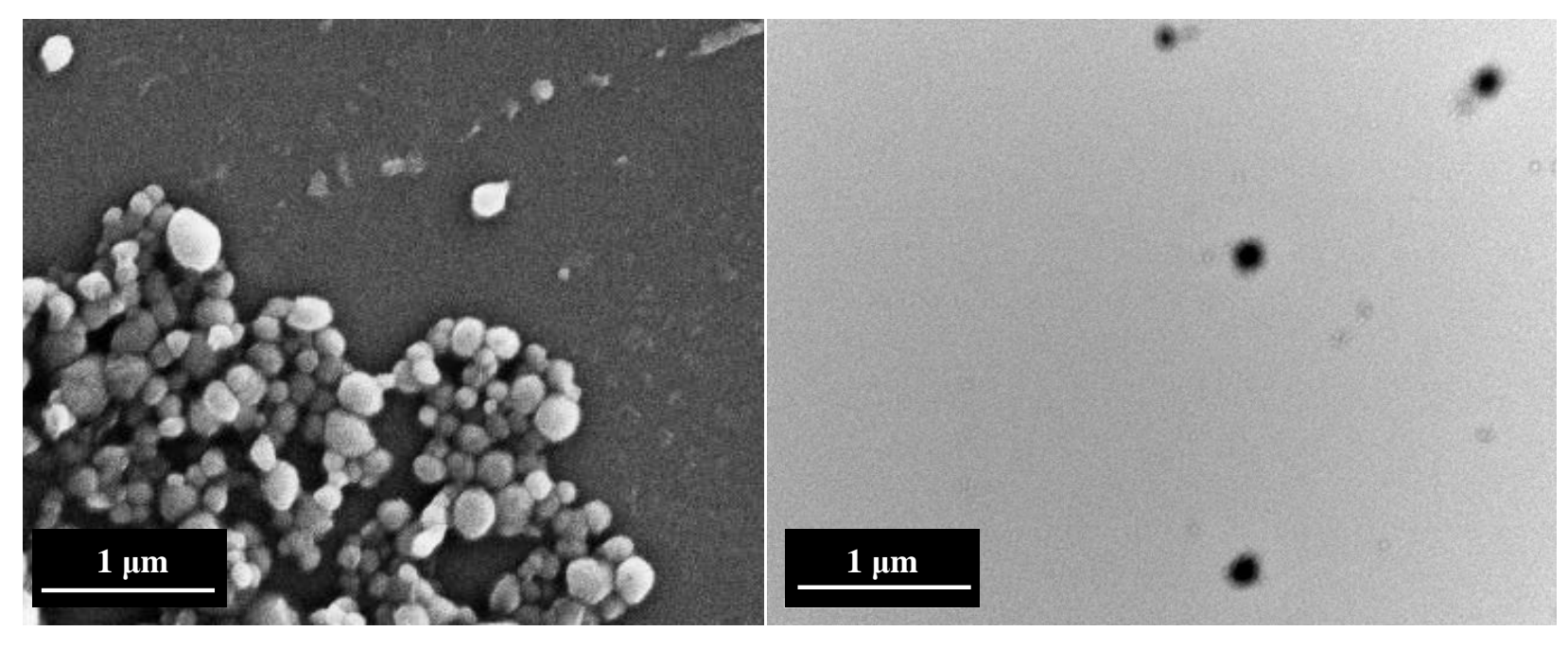

Fig. 8. Micrographs of the formed PCL NPs: (a) FEG-SEM image; (b) TEM image.

(a)

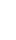

(

\section{$1 \mu \mathrm{m}$}

(1)

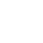


(a) $\mathrm{z}=30 \mathrm{~mm}$
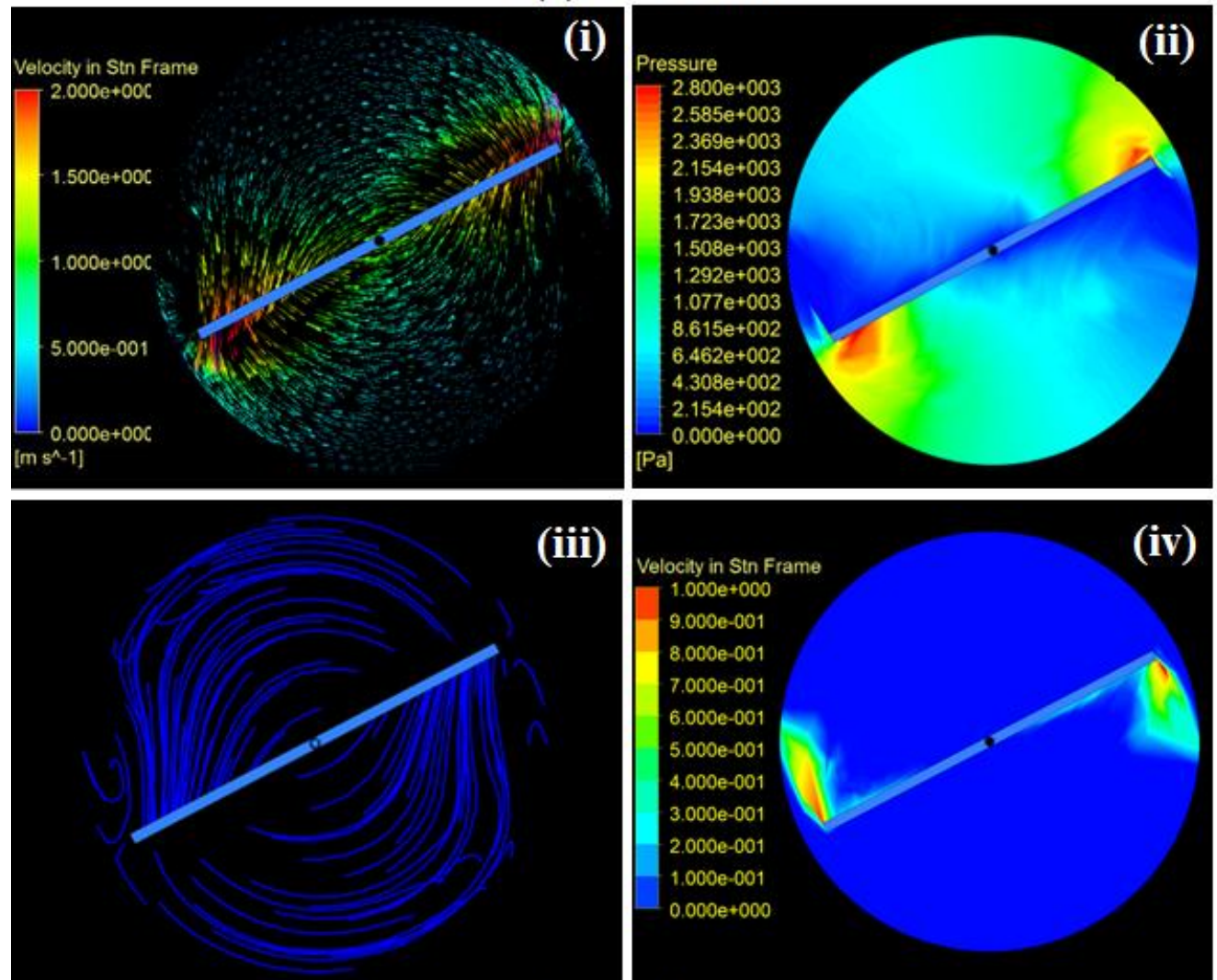

(b) $\mathrm{z}=\mathbf{2} \mathrm{mm}$
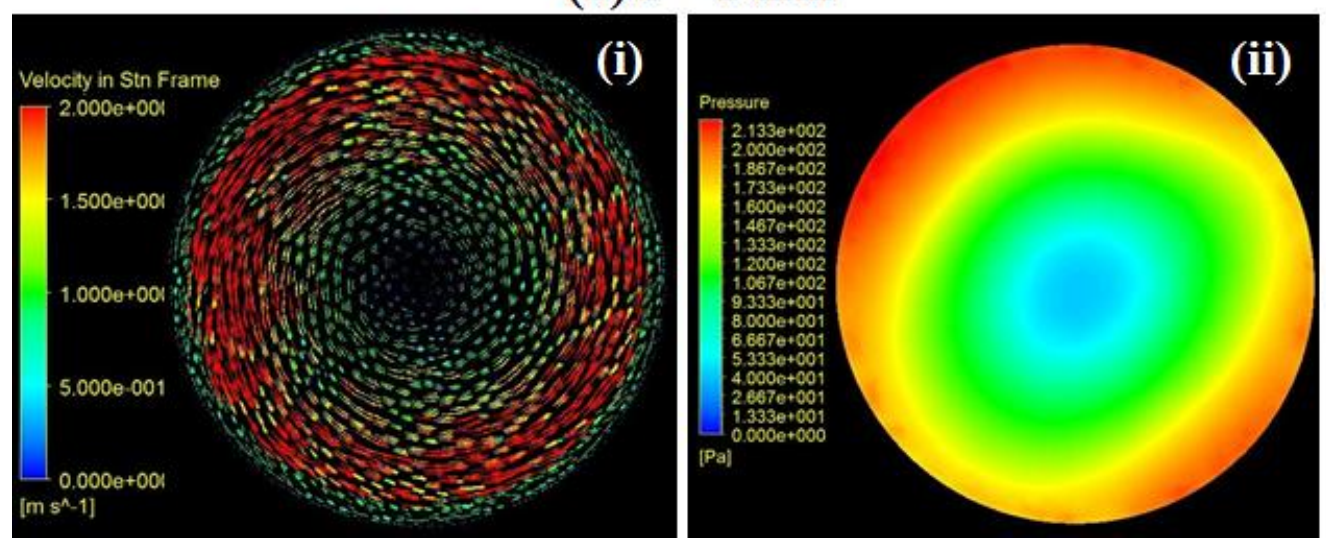

Fig. 9. Flow in the cell at $1300 \mathrm{rpm}$ rotation speed simulated at: (a) the cross section in the vicinity of the blades $(\mathrm{z}=30 \mathrm{~mm})$, and $(\mathrm{b})$ the cross section in the vicinity of the membrane $(\mathrm{z}=$ $2 \mathrm{~mm}$ ), with (i) velocity vectors, (ii) pressure contours, (iii) streamlines, (iv) vapour volume fraction contours (cavitation zones). All results are for counter-clockwise movement of blades and $\mathrm{z}$ is the vertical distance from the membrane surface. 


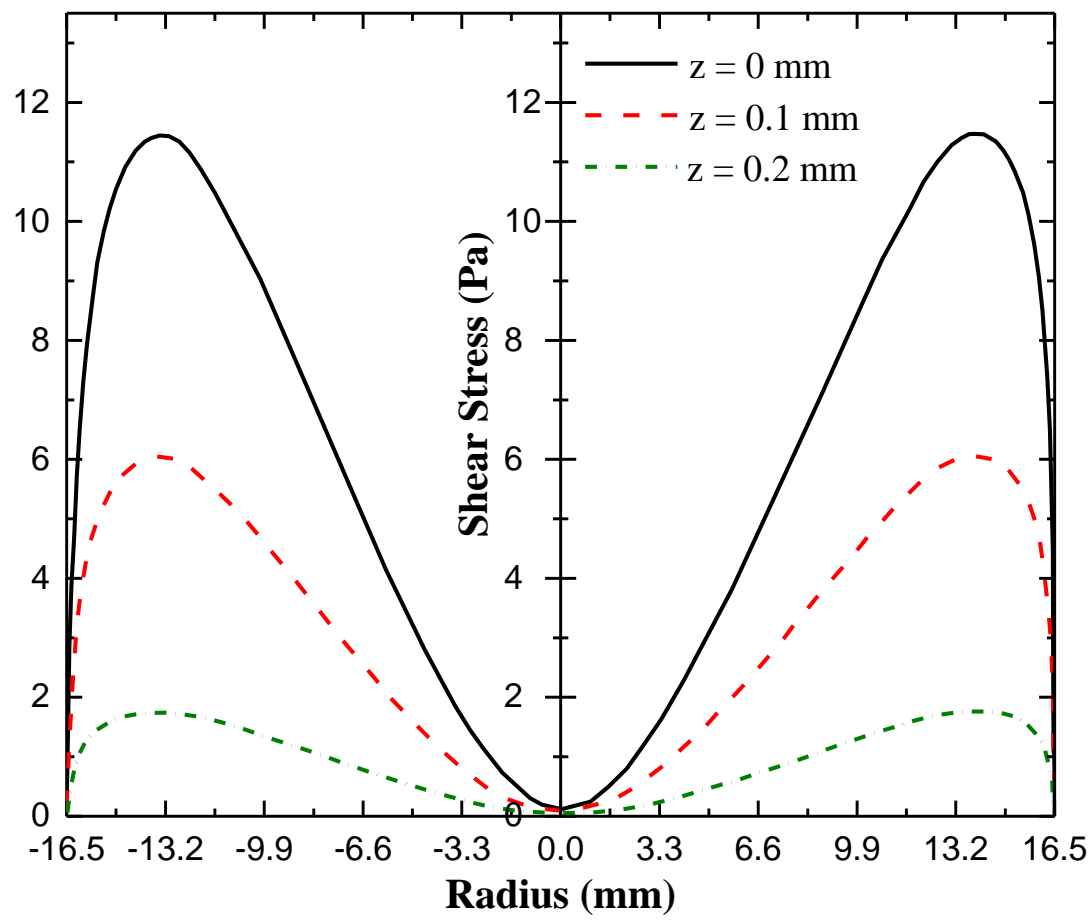

Fig. 10. Local shear stress as a function of the radial distance from the axis of rotation at a stirrer speed of $1300 \mathrm{rpm}$ for different distances from the membrane surface (CFD results). 

Supplementary material
Click here to download Supplementary Interactive Plot Data (CSV): Othman et al Supplementary Information.docx 西 (C): Othman et at (n) (a)

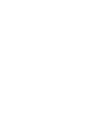

